\title{
Relationships Between Parenting and Dangerous Substance Use Behaviors Among Youth Experiencing Homelessness
}

\author{
Katie Massey Combs University of Colorado Boulder \\ Anamika Barman-Adhikari University of Denver \\ Stephanie Begun University of Toronto \\ Eric Rice University of Southern California
}

\begin{abstract}
A BSTRACT Objective: Understanding patterns of dangerous and illicit substance use among young parents who are homeless may provide insight into how best to support this highly vulnerable group and their children. This study examines the relationship between having a biological child and drug use among youth experiencing homelessness. Method: We used 4 waves of cross-sectional data from 1,010 youths ages 14-26 at 3 drop-in agencies serving youth experiencing homeless in Los Angeles, CA. Among participants, $23.8 \%$ of males and $28.9 \%$ of females had a biological child. We conducted multivariate logistic regression models for males and females on 4 substance use behaviors in the past month: binge drinking, using hard/illicit drugs, prescription drug misuse, and injection drug use. Results: Fathers had greater odds of hard drug use, prescription drug misuse, and injection drug use than males without children. There was no significant relationship between having a child and any of the four substance use behaviors for females. Conclusions: Findings suggest that having a child is not associated with higher risk of dangerous or illicit substance use for females. Results highlight the need to proactively engage young males in pregnancy prevention, parenting programs, and substance use treatment and prevention.
\end{abstract}

KEYWORDS: homeless youth, substance use, illicit drug use, parenting, gender differences

doi: $10.1086 / 707341$

In the United States, the broadest definition of homeless youth describes any individual 25 years of age or younger for whom it is not possible to live safely with a relative and who has no other safe alternative living arrangement (Federal Register, 2011). A 2018 study estimated that nearly 3.5 million young people ages 18-25 experienced homelessness in the U.S. during the prior year (Morton et al., 2018). Youth experiencing homelessness face a wide range of difficult life circumstances, including high rates of abandonment, foster care, and physical and/or sexual victimization

Journal of the Society for Social Work and Research, Volume 11, Number 1. 2334-2315/2020/1101-0001/\$10.00. (C) 2020 by the Society for Social Work and Research. All rights reserved. 
(Fisher, Florsheim, \& Sheetz, 2005; Keeshin \& Campbell, 2011; Stewart et al., 2004; Tyler \& Beal, 2010). They may also encounter intense social stigma based on multiple aspects of their identities, such as sexual orientation, gender/conformity, race/ ethnicity, and homelessness status. Experiences of stigma are further associated with low self-esteem, as well as increased loneliness and suicidal ideation (Kidd, 2004, 2006, 2007). High rates of substance use (Greene, Ennett, \& Ringwalt, 1999; Nyamathi, Hudson, Greengold, \& Leake, 2012; Rosenthal, Mallett, Milburn, \& Rotheram-Borus, 2008; Thompson, 2005; Wenzel, Tucker, Golinelli, Green, \& Zhou, 2010) and sexual risk behaviors (Halcón \& Lifson, 2004; Haley, Roy, Leclerc, Boudreau, \& Boivin, 2004; Rabinovitz, Desai, Schneir, \& Clark, 2010; Rice, Monro, Barman-Adhikari, \& Young, 2010; Tevendale, Lightfoot, \& Slocum, 2009; Walls \& Bell, 2011; Warf et al., 2013) are frequently described as consequences of this population's ongoing experiences of trauma, discrimination, and victimization (Christiani, Hudson, Nyamathi, Mutere, \& Sweat, 2008; Collins \& Barker, 2009).

Young people who are unstably housed also experience notably high rates of pregnancy/pregnancy involvement. Pregnancy rates among youth experiencing homelessness are 4-8 times greater than among housed counterparts (Cauce, Stewart, Whitbeck, Paradise, \& Hoyt, 2005; Crawford, Trotter, Hartshorn, \& Whitbeck, 2011; Greene \& Ringwalt, 1998; Haley et al., 2002; Tucker et al., 2012; Winetrobe et al., 2013). National and regional studies have consistently found that $30 \%-60 \%$ of young females experiencing homelessness have indicated past or current pregnancies (Halcón \& Lifson, 2004; Cauce et al., 2005; Crawford et al., 2011; Greene \& Ringwalt, 1998, Haley et al., 2002; Thompson, Bender, Lewis, \& Watkins, 2008) compared to $7 \%$ of young females who were stably housed (Greene \& Ringwalt, 1998). Other studies have found that $22 \%-43 \%$ of young males experiencing homelessness have reported impregnating someone in their lifetimes, of which they are aware (Winetrobe et al., 2013; Wagner, Carlin, Cauce, \& Tenner, 2001). Although limited research exists regarding the experiences and outcomes of having a biological child among youth experiencing homelessness, studies have found that roughly $25 \%-40 \%$ of homeless youths have reported being pregnant and/or having at least one biological child (Crawford et al., 2011; Narendorf, Jennings, \& Maria, 2016; Slesnick, Bartle-Haring, Glebova, \& Glade, 2006). Early maternal age among youth experiencing homelessness is of concern, as their babies are often born at low birth weights, prematurely, with prenatal exposure to drugs and alcohol, and are at high risk of being placed into the child welfare system (Novac, Paradis, Brown, \& Morton, 2006; Smid, Bourgois, \& Auerswald, 2010; Stein, Lu, \& Gelberg, 2000).

Furthermore, pregnancy and childbearing have been documented as destabilizing, stressful events in the lives of young people experiencing homelessness, who often report further-exacerbated health, mental, and social challenges-including higher rates of depression and histories of abuse and neglect-when compared to 
homeless peers who have not had children (Slesnick et al., 2006; Thompson et al., 2008). The challenges of raising a child in chaotic, privacy-lacking shelter and drop-in settings have been shown to worsen parents' (especially mothers') depressive symptoms and feelings of inadequacy as parents, and such challenges sometimes prompt them to turn to substance use as a stress-relief or "escape" tactic (Dworsky \& Meehan, 2012; Swick \& Williams, 2010).

High substance use rates are well documented among youth experiencing homelessness, with studies suggesting that many homeless youths engage in a wide range of especially dangerous substance use behaviors, such as binge drinking (Greene et al., 1999; Peterson, Baer, Wells, Ginzler, \& Garret, 2006); the use of methamphetamine (Greene \& Ringwalt, 1998; Nyamathi et al., 2010) and cocaine/crack (Greene et al., 1999; Nyamathi et al., 2012; Peterson et al., 2006); nonmedical use of prescription drugs (Al-Tayyib, Rice, Rhoades, \& Riggs, 2014; Barman-Adhikari, Al-Tayyib, Begun, Bowen, \& Rice, 2017); and injection drug use (Greene et al., 1999; Nyamathi et al., 2012; Parriott \& Auerswald, 2009; Roy et al., 2011). However, what is relatively unknown is whether these rates differ between homeless youths who have children and those who do not. Understanding patterns of substance use among young parents experiencing homelessness can guide and inform service provision and direct practitioners in how best to support this highly vulnerable group and their children.

Population-based data from housed adolescents suggest that substance use is often reduced among teens when they are pregnant but escalates postpartum (Substance Abuse and Mental Health Services Administration, 2011). Similarly, studies of youth experiencing homelessness suggest that mothers may reduce or cease substance use during pregnancy (Hathazi, Lankenau, Sanders, \& Bloom, 2009; Ruttan, Laboucane-Benson, \& Munro, 2012; Smid et al., 2010). However, little is known about substance use patterns among homeless young mothers following pregnancy-and particularly among homeless young fathers-even though these youths are a highrisk population. One exception is a study by Narendorf and colleagues (2016), which found no differences in the use of marijuana, alcohol, or other drugs among homeless young parents compared to homeless youths without children. However, two other studies found that young parents experiencing homelessness tend to use substances more than their nonparent peers (Schindler \& Coley, 2007; Slesnick et al., 2006). These mixed findings indicate that more research is needed to understand these associations and whether they hold true for other samples of youth experiencing homelessness.

Additionally, most studies of young parents focus solely on females. Given gender norms and gender role socialization (Grusec \& Hastings, 2014), which often casts childrearing as a female role, it is likely that the relationship between having children and dangerous substance use behaviors is different for homeless males than females. Additionally, gendered conceptions of parenting influence service availability, 
with more services typically available to support young homeless mothers than are available to fathers (Panter-Brick et al., 2014). As such, young mothers may be better supported to take on caregiving roles, whereas young fathers may have more difficulty navigating these major life changes without additional resources (Schindler \& Coley, 2007). The theory of situated fathering (Marsiglio \& Pleck, 2005) suggests that men's parenting is situated within the context of their physical and social spaces. Therefore, the lack of support for young fathers, coupled with the stressors of homelessness, might lead to greater substance use issues. Indeed, Narendorf and colleagues (2016) found that young homeless fathers were more likely than mothers to indicate current use of tobacco and marijuana. Similarly, Slesnick and colleagues (2006) found that homeless young fathers were more likely to indicate substance use than nonfathers, mothers, and nonmothers.

Taking a closer look at homeless males and their experiences with both having children and substance use may help tailor interventions for male homeless youth. Further, studies that have explored these relationships focused on general alcohol, tobacco, and marijuana use. The literature is even more scant in relation to illicit drugs or excessive drinking, which pose increased risks related to overdose, addiction, and transmission of infections than legally sold drugs and recreational use of alcohol and tobacco. Additionally, with the rise of opioid and prescription drug misuse (PDM) in the general population, understanding homeless youths' access to and use of these specific drugs is a meaningful distinction.

Several theories can help explain why having children might be associated with substance use among youth experiencing homelessness. For example, stress and coping theories (Pearlin, 1989) explain how specific life events-including parenting and the roles and strains associated with it-can increase the likelihood of experiencing stress, which is often associated with avoidant coping habits such as substance use. Becoming a parent is a major life event and may be especially disruptive when one is unstably housed. Additionally, due to the stress and demands of parenting and/or the grief associated with losing custody or contact with their children, the likelihood of dangerous substance use behaviors may increase for young parents who are homeless.

On the other hand, the motivational force of parenting may lead homeless young parents to use dangerous substances less frequently. For instance, the resilience principle (Luthar, 2006; Narayan, 2015) posits that individuals are able to overcome adversity and adapt to difficult circumstances. Research consistently suggests that parents who are homeless can maintain effective and positive parenting skills despite their homelessness, and many of them can maintain stability and even exit homelessness (Culhane, Metraux, Park, Schretzman, \& Valente, 2007; Haber \& Toro, 2004; Meadows-Oliver, 2006; Narayan, 2015). This is especially true for females who report actively seeking solutions that include obtaining an education and employment 
to help move their families out of homelessness (Hodnicki \& Horner, 1993; Menke \& Wagner, 1997).

\section{Current Study}

Understanding patterns of dangerous substance use-such as use of methamphetamines, binge drinking, PDM, and injection drug use-for young parents who are homeless has implications for research and service provision. Knowing if homeless young parents are more or less likely to engage in dangerous substance use behaviors also informs service provision and support services provided in shelters and drop-in centers. Moreover, it is necessary to know whether homeless young mothers and fathers need different support services regarding substance use and abuse.

Thus, the aim of this study is to explore whether homeless young people who have biological children are more likely to engage in dangerous substance use than their peers without biological children. Although the phenomenon of parenting while experiencing homelessness as a young person is understudied, existing research suggests that the experience of parenting is different for males and females. We therefore examined the relationship between having a biological child and substance use through a stratified approach with separate models for males and females. This is the first known investigation among a large sample of homeless youths to explore the relationship between having a biological child and specific forms of dangerous substance use-binge drinking, hard drug use, PDM, and injection drug use-including how such relationships may vary by biological sex.

\section{Method}

\section{Procedures and Participants}

Between October 2011 and June 2013, four waves of cross-sectional data were collected from youths (ages 14-26) at three Los Angeles, CA, drop-in centers serving youth who are homeless. The drop-in centers embrace a "low-barrier service structure," which means that any youth who self-identifies as homeless is eligible for agency services. Recruiters were present in the centers during drop-in hours on weekday afternoons. To be eligible for study participation, youths had to be 14-26 years old and must have received services at the agency on at least one prior occasion. Invitations to participate in the study were handed out when youths came to the agency to sign up for basic services. This recruitment strategy yielded a low refusal rate of only $9.3 \%$.

To maintain anonymous participation, verbal consent was received from participants. Those 18 years of age or older provided informed consent, and those under 18 provided informed assent. The University of Southern California Institutional Review Board approved all study procedures and waived parental consent since those 
under 18 were unaccompanied minors. Participants self-administered surveys via computers, which took approximately 60 minutes, and were compensated with a $\$ 20$ gift card. To avoid youths participating more than once, a consistent set of two research staff members were assigned to supervise the recruitment and data collection.

The original sample included 1,046 participants; of these, 19 did not complete a majority of the survey, and 17 identified as transgender. Given the small number of transgender participants, and that our research questions inherently involved both biological sex (e.g., the possibility to become pregnant) and lived experiences around gender identity, these cases were excluded. Thus, our analyses included 1,010 youths who completed the survey and identified as male or female. The average age of participants was 21.4 years $(S D=2.2$ ); $24.3 \%$ identified as LGBQ (lesbian, gay, bisexual, queer/questioning), and $72.3 \%$ identified as male. The sample was racially diverse, with $39.0 \%$ of participants identifying as White, $24.1 \%$ as Black, $19.3 \%$ as mixed race, and $13.5 \%$ as Latino. Among participants, two thirds had a high school diploma or GED, just over a tenth were employed, and one third had a history of foster care. Participants reported an average age of 16.7 years old $(S D=4.0)$ when they first became homeless or did not have a regular place to stay.

\section{Measures}

Dependent variables. The dependent variables were engagement in binge drinking, hard drug use, PDM, and injection drug use in the past month, which were assessed by asking if the participant had engaged in the specific behavior 0-40 or more times in the past 30 days. Recent binge drinking included five or more drinks of alcohol in a row or within a couple of hours; recent hard drug use included any use of illicit substances, including methamphetamines, cocaine, crack, heroin, or ecstasy; PDM included taking prescription drugs (e.g., OxyContin, Percocet, Vicodin, codeine, Adderall, Ritalin, or Xanax) without a doctor's prescription or using more of the drug than prescribed; and injection drug use included using a needle to inject any illicit drug into one's body. Given that distributions were skewed, that endorsements of each behavior represented at most one third of the sample, and that any engagement in these substance use behaviors carries substantial risk, these variables were dichotomized. Only 3.5\% of participants had missing data on binge drinking, $1.9 \%$ on hard drug use, $3.0 \%$ on PDM, and $2.8 \%$ on injection drug use.

Just over one third of participants reported binge drinking and hard drug use, and roughly $20 \%$ and $10 \%$ reported PDM and injection drug use, respectively. More than half $(57.6 \%)$ of participants engaged in one or more of the four types of substance use behaviors examined, with $28.5 \%$ engaging in one type, $16.2 \%$ in two, $8.8 \%$ in three, and $3.7 \%$ engaging in all four. There was substantial overlap in those reporting injection drug, PDM, and hard drug use; 95\% of participants who used 
injection drugs and $72 \%$ who misused prescription drugs also reported hard drug use. Among those who used hard drugs, however, 25\% used injection drugs and $40 \%$ used PDM. Thus, PDM and injection drugs were different subsets of hard-drug users (62\% of injection-drug users also misused prescription drugs). This overlap was expected, as injection drugs and hard drugs are similar; however, the use of needles to inject drugs infers different and greater risks (e.g., HIV, hepatitis C). We thus chose to analyze these behaviors separately. Although PDM is often categorized as hard/illicit drug use, because access to these drugs can be legal, we also examined this outcome separately.

Independent variable and covariates. The primary independent variable of interest was having a biological child ("How many biological children have you had in your lifetime?”), which was coded into a dichotomous variable assessing whether a participant reported having at least one child. Participants who had no children, however, may have had/caused a pregnancy that did not result (or had yet to result) in a birth. Covariates were self-reported demographic data and included age, race/ ethnicity (White, Black, mixed race, Latino), sexual orientation $(L G B Q=1$, straight/ heterosexual $=0$ ), education (high school diploma or $G E D=1$, less education $=0$ ), history of foster care (vs. no history of foster care), and current employment (vs. not employed). A total of $8.5 \%$ of participants had missing data on one or more of the covariates or the independent variable; less than $2 \%$ of participants had missing data on gender, sexual orientation, race, education, and current employment; $2.4 \%$ of participants had missing data on whether they had a child; and $5.4 \%$ had missing data on foster care status.

\section{Analysis}

For all analyses, we used a stratified approach analyzing males and females separately. Differences between participants with and without children were explored on each of the covariates and dependent variables through chi-square and $t$-tests (Table 1). For multivariate analyses, we conducted binary logistic regression models on each of the four dependent variables for males and females separately. These models included covariates and the independent variable: sexual orientation, racial identity, age, history of foster care, education, current employment, and having a biological child. Given the small level of missingness, we used listwise deletion to handle missing data. Although listwise deletion can reduce power and introduce bias if data are not missing at random, in this data set, no single variable had more than 5\% missing, and studies suggest that a missing rate of 5\%-10\% or less is inconsequential (Bennett, 2001). Finally, we reported the Nagelkerke $R^{2}$ for these analyses, which is one of the various pseudo $R^{2}$ statistics. For regression models with a categorical dependent variable, it is not possible to compute a single $R^{2}$ 
Table 1

Descriptive Statistics by Participants With and Without Biological Children

\begin{tabular}{|c|c|c|c|c|c|c|c|}
\hline \multirow[b]{2}{*}{ Variable } & \multirow[b]{2}{*}{$\begin{array}{c}\text { Total } \\
(N=1,010)\end{array}$} & \multicolumn{2}{|c|}{$\begin{array}{c}\text { Males } \\
(n=735,72.8 \%)\end{array}$} & \multirow[b]{2}{*}{$\begin{array}{c}\chi^{2} / \\
t \text {-test }\end{array}$} & \multicolumn{2}{|c|}{$\begin{array}{c}\text { Females } \\
(n=275,27.2 \%)\end{array}$} & \multirow[b]{2}{*}{$\begin{array}{c}\chi^{2} \\
t \text {-test }\end{array}$} \\
\hline & & $\begin{array}{c}\text { Child } \\
(n=171)\end{array}$ & $\begin{array}{l}\text { No Child } \\
(n=549)\end{array}$ & & $\begin{array}{l}\text { Child } \\
(n=77)\end{array}$ & $\begin{array}{l}\text { No Child } \\
(n=189)\end{array}$ & \\
\hline Age (M [SD]) & $21.4(2.2)$ & $22.03(2.0)$ & $21.4(2.1)$ & $3.4^{* *}$ & $21.8(2.2)$ & $20.6(2.0)$ & $4.4^{\text {*****}}$ \\
\hline \multicolumn{8}{|l|}{ Sexual orientation } \\
\hline LGBQ & $24.3 \%$ & $10.70 \%$ & $16.9 \%$ & 3.8 & $43.4 \%$ & $50.3 \%$ & 1.0 \\
\hline Straight & $75.7 \%$ & $89.30 \%$ & $83.1 \%$ & - & $56.6 \%$ & $49.7 \%$ & - \\
\hline \multicolumn{8}{|l|}{ Race } \\
\hline $\mathrm{AI} / \mathrm{AN}$ & $2.9 \%$ & $1.2 \%$ & $3.6 \%$ & 2.7 & $2.6 \%$ & $2.6 \%$ & 0.0 \\
\hline Asian & $0.6 \%$ & $0.6 \%$ & $0.4 \%$ & 0.2 & $2.6 \%$ & $0.5 \%$ & 2.1 \\
\hline Black & $24.1 \%$ & $21.1 \%$ & $24.5 \%$ & 0.8 & $26.0 \%$ & $25.9 \%$ & 0.0 \\
\hline $\mathrm{NH} / \mathrm{PI}$ & $0.6 \%$ & $1.2 \%$ & $0.4 \%$ & 1.5 & $0.0 \%$ & $1.1 \%$ & 0.8 \\
\hline White & $39.0 \%$ & $40.4 \%$ & $42.7 \%$ & 0.3 & $26.0 \%$ & $36.0 \%$ & 2.5 \\
\hline Latino & $13.5 \%$ & $14.0 \%$ & $12.8 \%$ & 0.2 & $22.1 \%$ & $9.0 \%$ & $8.4^{* *}$ \\
\hline Mixed & $19.3 \%$ & $21.6 \%$ & $15.7 \%$ & 3.2 & $20.8 \%$ & $24.9 \%$ & 0.6 \\
\hline HS/GED & $68.4 \%$ & $64.1 \%$ & $69.3 \%$ & 1.6 & $63.6 \%$ & $70.2 \%$ & 1.1 \\
\hline Employed & $12.3 \%$ & $18.6 \%$ & $10.7 \%$ & $7.2^{* *}$ & $16.9 \%$ & $9.5 \%$ & 2.9 \\
\hline Foster care & $33.5 \%$ & $39.1 \%$ & $28.6 \%$ & $6.3^{*}$ & $54.1 \%$ & $34.1 \%$ & $8.8^{* *}$ \\
\hline \multicolumn{8}{|l|}{ Substance use } \\
\hline Binge drinking & $38.6 \%$ & $46.1 \%$ & $41.2 \%$ & 1.2 & $18.4 \%$ & $32.1 \%$ & $5.0^{*}$ \\
\hline Hard drugs & $35.6 \%$ & $48.5 \%$ & $34.4 \%$ & $10.7^{\text {*** }}$ & $31.2 \%$ & $29.3 \%$ & 0.1 \\
\hline PDM & $19.2 \%$ & $28.0 \%$ & $17.4 \%$ & $8.9^{* *}$ & $13.2 \%$ & $21.9 \%$ & 2.7 \\
\hline Injection drugs & $9.8 \%$ & $15.2 \%$ & $8.3 \%$ & $6.6^{*}$ & $13.0 \%$ & $7.5 \%$ & 2.0 \\
\hline
\end{tabular}

Note. $M=$ mean; $S D$ = standard deviation; $L G B Q=$ lesbian, gay, bisexual, queer/questioning; AI/AN = American Indian/Alaska Native; NH/PI = Native Hawaiian/Pacific Islander; HS/GED = high school/GED; PDM = prescription drug misuse.

${ }^{*} p<.05$.

*** $p<.01$.

${ }^{* * *} p<.001$.

statistic equivalent to that of a linear regression model; thus, pseudo $R^{2}$ statistics are approximations. The Nagelkerke $R^{2}$ is a version of the Cox \& Snell $R^{2}$ that adjusts the full range of values to be on a scale of $0-1$.

\section{Results}

\section{Descriptive and Bivariate Statistics}

Table 1 details the demographic characteristics of participants with and without a biological child. One quarter of the sample had a child $(n=248,25.2 \%)$, with 
similar rates for males $(23.8 \%)$ and females $(28.9 \%): \chi^{2}(1)=2.79, p=.10$. Of participants reporting a biological child, $46.2 \%$ of males and $40.3 \%$ of females reported having more than one child. About one quarter (24.2\%) of fathers and one third of mothers (37.7\%) reported that at least one of their children was currently staying with them. Although the sample largely identified as male (72.8\%) and straight/ heterosexual (75.7\%), participants were racially diverse with roughly $38.2 \%$ identifying as White, $23.3 \%$ as Black, and $19.1 \%$ as mixed race. Males and females who had a biological child were more likely to be older and to have experienced foster care (Table 1). Males with biological children were more likely to be employed and to report hard drug, prescription drug, and injection drug use over the past month, compared to males without children. Females with biological children were more likely to identify as Latina and were less likely to report binge drinking than females without children (Table 1).

\section{Multivariate Analyses}

Table 2 shows results of the multivariate models, split by males and females, which included sexual orientation, racial identity, age, history of foster care, education, current employment, and having a biological child.

Binge drinking. Having a biological child was not significantly related to binge drinking for males or females in multivariate models that controlled for covariates. Identifying as Black was associated with less likelihood of binge drinking for both males-odds ratio $(O R)=.38,95 \%$ confidence interval (CI) $[.25, .59]$ - and females$\mathrm{OR}=.44,95 \% \mathrm{CI}[.20, .93]$. Also, identifying as LGBQ was associated with greater odds of binge drinking for females $(O R=1.97,95 \% \mathrm{CI}[1.10,3.52])$ but a trend of statistically lower odds for males $(O R=.63,95 \%$ CI $[.40,1.00], p=.05)$.

Hard drug use. Males with biological children had greater odds of using hard drugs (i.e., methamphetamines, cocaine, crack, ecstasy, or heroin) in the past month compared to males without biological children $(\mathrm{OR}=1.87$, $95 \% \mathrm{CI}[1.28,2.75])$, though no significant relationship was found among females. Identifying as Black was associated with decreased odds of hard drug use for males (OR $=.45,95 \% \mathrm{CI}[.29, .70])$ and females $(O R=.17,95 \% \mathrm{CI}[.07, .41])$. The relationship between hard drug use and the covariates (i.e., foster care, education, and sexual orientation) differed in models for males and females. For males, a history of foster care was associated with increased odds $(O R=1.60,95 \% \mathrm{CI}[1.12,2.27])$ of hard drug use, and a high school diploma (or GED) was associated with reduced odds (OR $=.67,95 \%$ CI $[.47, .95])$, though these covariates were not significant for females. LGBQ females had odds almost two times greater for using hard drugs than females who identified as straight/ heterosexual (OR $=1.92,95 \% \mathrm{CI}[1.09,3.38])$.

Prescription drug misuse. Males with biological children had odds of PDM more than two times greater than males who did not have children $(O R=2.20,95 \% \mathrm{CI}$ $[1.42,3.42])$, though this was not a significant association for females. Race variables 
Table 2

Multivariate Logistic Regressions Stratified by Males and Females $(N=1,010)$

\begin{tabular}{|c|c|c|c|c|c|c|}
\hline \multirow[b]{3}{*}{ Variable } & \multicolumn{3}{|c|}{ Males } & \multicolumn{3}{|c|}{ Females } \\
\hline & \multirow[b]{2}{*}{ OR } & \multicolumn{2}{|c|}{$95 \% \mathrm{CI}$} & \multirow[b]{2}{*}{$O R$} & \multicolumn{2}{|c|}{$95 \% \mathrm{CI}$} \\
\hline & & LL & UL & & LL & UL \\
\hline \multicolumn{7}{|l|}{ Binge drinking } \\
\hline LGBQ (1) & 0.63 & 0.40 & 1.00 & $1.97^{*}$ & 1.10 & 3.52 \\
\hline Black (1) & $0.38^{* * * *}$ & 0.25 & 0.59 & $0.44^{*}$ & 0.20 & 0.93 \\
\hline Latino/Hispanic (1) & 0.85 & 0.51 & 1.39 & 0.46 & 0.17 & 1.23 \\
\hline Mixed race (1) & 0.65 & 0.42 & 1.02 & $0.38^{*}$ & 0.18 & 0.83 \\
\hline Age & 0.97 & 0.90 & 1.04 & 0.92 & 0.80 & 1.07 \\
\hline Foster care & 0.72 & 0.51 & 1.03 & 0.74 & 0.39 & 1.39 \\
\hline High school/GED & 1.21 & 0.85 & 1.72 & 1.46 & 0.76 & 2.83 \\
\hline Employed (1) & 1.30 & 0.79 & 2.13 & 2.00 & 0.70 & 5.70 \\
\hline Has biological child (1) & 1.26 & 0.86 & 1.86 & 0.69 & 0.33 & 1.46 \\
\hline Nagelkerke $R^{2}$ & 0.07 & - & - & 0.13 & - & - \\
\hline \multicolumn{7}{|l|}{ Hard drug use } \\
\hline LGBQ (1) & 1.56 & 1.00 & 2.44 & $1.92^{*}$ & 1.09 & 3.38 \\
\hline Black (1) & $0.45^{*}$ & 0.29 & 0.70 & $0.17^{* * * *}$ & 0.07 & 0.41 \\
\hline Latino/Hispanic (1) & 0.80 & 0.48 & 1.34 & 0.69 & 0.29 & 1.67 \\
\hline Mixed race (1) & 0.65 & 0.41 & 1.02 & 0.72 & 0.36 & 1.44 \\
\hline Age & 1.04 & 0.96 & 1.13 & 1.00 & 0.87 & 1.15 \\
\hline Foster care (1) & $1.60^{* * *}$ & 1.12 & 2.27 & 1.41 & 0.76 & 2.60 \\
\hline High school/GED (1) & $0.67^{*}$ & 0.47 & 0.95 & 1.37 & 0.73 & 2.55 \\
\hline Employed (1) & 0.91 & 0.55 & 1.49 & 1.59 & 0.61 & 4.18 \\
\hline Has biological child (1) & $1.87^{* *}$ & 1.28 & 2.75 & 1.27 & 0.64 & 2.51 \\
\hline Nagelkerke $R^{2}$ & 0.14 & - & - & 0.14 & - & - \\
\hline \multicolumn{7}{|l|}{ PDM } \\
\hline LGBQ (1) & 1.69 & 1.00 & 2.87 & 1.47 & 0.76 & 2.81 \\
\hline Black (1) & $0.45^{* *}$ & 0.26 & 0.79 & $0.22^{* *}$ & 0.08 & 0.59 \\
\hline Latino/Hispanic (1) & 0.74 & 0.40 & 1.36 & $0.23^{*}$ & 0.06 & 0.84 \\
\hline Mixed race (1) & $0.53^{*}$ & 0.30 & 0.95 & $0.43^{*}$ & 0.19 & 0.97 \\
\hline Age & 1.07 & 0.98 & 1.18 & 0.93 & 0.79 & 1.10 \\
\hline Foster care (1) & 0.70 & 0.44 & 1.10 & 1.21 & 0.59 & 2.46 \\
\hline High school/GED (1) & 1.03 & 0.66 & 1.59 & 0.87 & 0.42 & 1.80 \\
\hline Employed (1) & 1.18 & 0.63 & 2.23 & 0.59 & 0.22 & 1.61 \\
\hline Has biological child (1) & $2.20^{* * * *}$ & 1.42 & 3.42 & 0.64 & 0.27 & 1.49 \\
\hline Nagelkerke $R^{2}$ & 0.08 & - & - & 0.12 & - & - \\
\hline
\end{tabular}


Table 2 (Continued)

\begin{tabular}{|c|c|c|c|c|c|c|}
\hline \multirow[b]{3}{*}{ Variable } & \multicolumn{3}{|c|}{ Males } & \multicolumn{3}{|c|}{ Females } \\
\hline & \multirow[b]{2}{*}{ OR } & \multicolumn{2}{|c|}{$95 \%$ CI } & \multirow[b]{2}{*}{ OR } & \multicolumn{2}{|c|}{$95 \% \mathrm{CI}$} \\
\hline & & LL & UL & & LL & UL \\
\hline \multicolumn{7}{|l|}{ Injection drug use } \\
\hline LGBQ (1) & 1.78 & 0.93 & 3.43 & 0.76 & 0.30 & 1.94 \\
\hline Black (1) & $0.18^{* *}$ & 0.06 & 0.52 & $0.05^{* *}$ & 0.01 & 0.37 \\
\hline Latino/Hispanic (1) & 1.16 & 0.58 & 2.31 & 0.21 & 0.04 & 1.02 \\
\hline Mixed race (1) & $0.38^{*}$ & 0.16 & 0.89 & $0.12^{* *}$ & 0.03 & 0.57 \\
\hline Age & 1.11 & 0.98 & 1.26 & 1.10 & 0.88 & 1.38 \\
\hline Foster care (1) & 1.23 & 0.70 & 2.18 & 2.20 & 0.80 & 6.06 \\
\hline High school/GED (1) & 0.68 & 0.39 & 1.19 & 0.99 & 0.35 & 2.77 \\
\hline Employed (1) & 1.36 & 0.55 & 3.37 & 0.44 & 0.13 & 1.49 \\
\hline Has biological child (1) & $1.96^{*}$ & 1.11 & 3.47 & 1.58 & 0.54 & 4.58 \\
\hline Nagelkerke $R^{2}$ & 0.11 & - & - & 0.23 & - & - \\
\hline
\end{tabular}

Note. $\mathrm{OR}=$ odds ratio; $\mathrm{CI}=$ confidence interval; $\mathrm{LL}=$ lower limit; $\mathrm{UL}=$ upper limit; $\mathrm{LGBQ}=$ lesbian, gay, bisexual, queer/questioning; PDM = prescription drug misuse. For each covariate, the reference category was the alternative response(s). For LGBQ, the reference category was "straight"; for foster care, the reference category was "never been in foster care"; for high school/GED, the reference category was "less than a GED or high school diploma"; for employed, the reference category was "not currently employed."

${ }^{*} p<.05$.

${ }^{* *} p<.01$.

**** $p<.001$.

were the only significant covariates in PDM models. Compared to their White counterparts, Black males and females had decreased odds of PDM $\left(O R_{\text {males }}=.45\right.$, $\left.95 \% \mathrm{CI}_{\text {males }}[.26, .79] ; O \mathrm{R}_{\text {females }}=.22,95 \% \mathrm{CI}_{\text {females }}[.08, .59]\right)$, Latinas had decreased odds $\left(O R_{\text {females }}=.23,95 \% \mathrm{CI}_{\text {females }}[.06, .84]\right)$, and mixed-race participants had decreased odds of PDM as well $\left(O R_{\text {males }}=.53,95 \% \mathrm{CI}_{\text {males }}[.30, .95] ; O R_{\text {females }}=.43,95 \% \mathrm{CI}_{\text {females }}\right.$ $[.19, .97])$.

Injection drug use. Similar to PDM, for injection drugs, males with biological children had odds almost two times greater than males who did not have children (OR $=1.96,95 \% \mathrm{CI}[1.11,3.47])$, though having a biological child did not have a significant association for females. Identifying as Black $\left(O R_{\text {males }}=.18,95 \% \mathrm{CI}_{\text {males }}[.06\right.$, $\left..52] ; O R_{\text {females }}=.05,95 \% \mathrm{CI}_{\text {females }}[.01, .37]\right)$ or mixed race $\left(O R_{\text {males }}=.38,95 \% \mathrm{CI}_{\text {males }}[.16\right.$, $\left..89] ; O R_{\text {females }}=.12,95 \% \mathrm{CI}_{\text {females }}[.03, .57]\right)$ was again associated with reduced odds of injection drug use for both males and females compared to their counterparts identifying as White. 


\section{Discussion}

Results from this study identify differences in dangerous and/or illicit substance use (i.e., binge drinking, hard drug use, PDM, and injection drug use in the past month) among homeless youths with and without biological children. It also adds a deeper understanding of differences between males and females regarding the relationship between substance use and having a child. Previous research on substance use among both housed (Substance Abuse and Mental Health Services Administration, 2011; Chapman \& Wu, 2013) and unstably housed youth (Hathazi et al., 2009; Slesnick et al., 2006; Schindler \& Coley, 2007) finds that young parents often increase their substance use after a pregnancy or having a child. In multivariate analyses among our sample, females with a child were not more likely to engage in any of the four substance use behaviors compared to females without children, though males with children were significantly more likely to engage in three of the four substance use behaviors than males without children. Having a biological child was not associated with increased risk of binge drinking for males or females. However, for the three forms of illicit drug use, having a child was related to roughly two times greater odds for males, but no increased odds for females.

The lack of associations between having a child and dangerous or illicit substances for females suggests that having a biological child does not necessarily represent an increased risk of dangerous or illicit substance use behaviors for young mothers experiencing homelessness. This finding provides some support for the resilience principle (Luthar, 2006; Narayan, 2015), especially for females, and validates previous findings (Hodnicki \& Horner, 1993; Menke \& Wagner, 1997) that mothers are more likely to engage in problem-solving and use coping skills to remedy their problems, which are behaviors associated with decreased substance use and abuse. However, the strength and hope that these young people demonstrate can only be realized and sustained by providing them appropriate external support and resources to meet both their basic and psychosocial needs.

Although it is not possible to discern from our data why young fathers reported more illicit substance use than males without children, possible explanations for stronger associations among young homeless males with children are that they simply engage in and experience a wider range of risky behaviors and life situations (Hathazi et al., 2009; Narendorf et al., 2016; Slesnick et al., 2006). For example, the few studies that have looked at homeless young fathers have found that they were more likely to be involved in the criminal justice system and more likely to be sleeping on the streets relative to males without children (Hathazi et al., 2009; Narendorf et al., 2016; Slesnick et al., 2006). Additionally, Narendorf et al. (2016) found that homeless fathers were more likely to report attention-deficithyperactivity disorder and that this group is tasked with engaging in a wider range of survival strategies when compared to homeless young mothers. 
Another potential explanation is that males tend to report using services less frequently (Berdahl, Hoyt, \& Whitbeck, 2005) and are not targets of services for young parents. It is possible that because most programs and services designed for parents who are homeless are geared toward females, males are left out of the service "loop," and consequently, the stability that comes with receipt of such services. This is consistent with the theory of situated fathering (Marsiglio \& Pleck, 2005) and highlights the contextual constraints-such as institutional practices and lack of social support-that young fathers who are homeless encounter and that might increase their likelihood of engaging in maladaptive behaviors such as substance use.

Several patterns also emerged among covariates in this sample. Male and female participants of color (most consistently participants identifying as Black) had significantly lower odds for each substance use behavior. This is consistent with previous research, which has found that Black youths who experience homelessness are less likely to engage in substance use than their White counterparts (Bousman et al., 2005; Nyamathi et al., 2012; Rice, Milburn, \& Monro, 2011). Several factors may explain or contribute to these relationships. First, racial differences in dangerous substance use may be related to varying drivers of homelessness by race. Young people of color are more likely to be driven into homelessness by economic factors within their family and their broader community and social network, whereas for White youth, behavioral and substance use problems are more common drivers into homelessness and may contribute to "wearing out" their support systems, which could also lead to a White homeless population with more severe substance use problems. For example, a study (Auerswald \& Puddefoot, 2012) comparing Black and White homeless youth in San Francisco, CA, found that Black youths reported widespread use of marijuana and alcohol but reported that injection drug use, heroin, crack, cocaine, and speed were highly stigmatized within their community and they were more likely to reject these substances (Auerswald \& Puddefoot, 2012). On the other hand, White youths reported no such stigmatization, and injection drug use in particular was accepted as a way of life among this group. The same study also found that Black youths were more likely than White youths to remain in contact with their families. Maintaining connections with home-based peers and supportive family members has a positive function for most youths who are homeless (Rice et al., 2011; Wenzel et al., 2010). For example, Rice, Milburn, and Rotheram-Borus (2007) found that more connections with prosocial peers reduced hard drug use (i.e., cocaine, methamphetamine, and heroin) over time. Likewise, other studies have found that youths who are connected with family members are less likely to report engaging in any substance use (Tyler, 2008; Wenzel et al., 2010). Given that so many Black youths have reported maintaining connections with their families, services targeted toward maintaining and encouraging these relationships should be prioritized. On 
the other hand, effective interventions to reduce substance use among White youths may need to focus on connecting them to effective substance use prevention and recovery programs.

Unlike race, sexual orientation had differing patterns for males and females. Identifying as LGBQ increased the odds of binge drinking and hard drug use for females, and it reduced or had no association in respective models for males. It is notable that roughly half of females (48.2\%) and only $15.3 \%$ of males in our sample identified as LGBQ. The varying association of sexual orientation within models for males and females could be related to the increased proportion of female youth identifying as LGBQ and the additional stressors that come with multiple marginalized identities. This may suggest a need for more targeted intervention programs. Regardless, these findings underscore an opportunity to tailor services to this subpopulation. Future research confirming this association and exploring how such adaptations could better reach this group is essential.

The primary implication of this study is that in order to address substance use among youth experiencing homeless, an integrated approach with a clear focus on engaging young males in both the development and provision of services is essential. Young males experiencing homelessness, and particularly those with biological children, appear to have increased risk, yet they are less likely to engage in services or to be the targets of services. Even among the general population, most parenting programs do not seek to engage fathers (Panter-Brick et al., 2014). The experience of parenting is fundamentally different for males and females. This is reflected in that children are more likely to live with their mothers and that the majority of parenting programs are geared toward mothers. As a result, programs that seek to engage young fathers who are homeless will likely need to be tailored to address the unique and often complicated circumstances associated with their pregnancy involvement and parenting (e.g., sexual abuse, stressors associated with pregnancy, etc.). Simply seeking to engage males in current parenting programs for at-risk youth, which are primarily targeted to females or housed young fathers, may be irrelevant for homeless young fathers, who may not have the option to live in the same home as their child and who are consistently concerned about meeting their own basic needs. Additionally, comprehensive approaches that support the prevention of behavioral health problems is essential. Issues around substance use, sexual health, and parenting are intertwined, yet programs tend to focus on specific problem outcomes. Indeed, among teen pregnancy prevention programs, research has shown that programs with a holistic approach (e.g., including components on values, refusal skills, and healthy relationships) are most effective (Goesling, Colman, Trenholm, Terzian, \& Moore, 2014; Office of Adolescent Health, 2017). Integrating reproductive health components, such as screenings or referrals, within substance use programs (and vice versa) could be a key intervention point that is currently underused. 


\section{Limitations}

Although this study presents novel findings pertaining to parenting among a highly vulnerable population, there are several limitations of our study. First, our findings may not be generalizable to other populations of homeless youth. Los Angeles is a service-rich environment and has a range of service options available for homeless youth. It is possible that our participants are more service-engaged and therefore less resource-poor than homeless youth in other cities. Our data are also self-reported and therefore might be biased given the sensitive nature of our questions. Additionally, we combined multiple cross-sectional data, which was collected over time from the same drop-in centers. To avoid duplication of surveys, a consistent set of two research staff members were assigned to supervise participant recruitment and data collection throughout the 2 years of the study. However, even with such gatekeeping procedures, there is still potential for youths to be accidentally interviewed more than once.

Furthermore, of the participants who reported having children, it is unknown how many of these pregnancies were unintended or the result of sexual abuse. Researchers have found that pregnancies among homeless youth are often unintended or result from sexual abuse (Begun, 2015), which can influence postpartum drug use. Also, we were limited by the nature of the data and have no information about how many participants had custody of their children or the stressors associated with parenting that may partially explain engagement in substance use behaviors. Finally, due to the cross-sectional design, we were unable to determine the temporal relationship between their reports of drug use and history of having children. Therefore, we cannot assume a cause-and-effect relationship between having a child and substance use, or that having a child is a function of greater substance use. Given that this study does not have data from before participants had children, we can only speak to statistical relationships between having a biological child and the four substance use behaviors studied.

\section{Conclusion}

In multivariate models controlling for various demographic and risk factors, having a child was associated with approximately twice the odds of hard drug use, PDM, and injection drug use for young fathers experiencing homelessness compared to males without biological children. For females, however, these relationships were not significant, suggesting that having a child may not be related to increased risk for dangerous or illicit substance use for females. The increased odds of substance use for fathers, but not mothers, may be related to different risk and protective profiles, or that more services are available to young mothers than to young fathers. Regardless, these findings highlight the need for comprehensive and integrated approaches that support all young parents experiencing homelessness and the need for interventions that specifically seek to engage young males. 


\section{Author Notes}

Katie Massey Combs, PhD, is a research associate at the University of Colorado Boulder Institute of Behavioral Science and a research assistant at the University of Denver Graduate School of Social Work.

Anamika Barman-Adhikari, $\mathrm{PhD}$, is an assistant professor at the University of Denver Graduate School of Social Work.

Stephanie Begun, $\mathrm{PhD}$, is an assistant professor at Factor-Inwentash Faculty of Social Work, University of Toronto.

Eric Rice, PhD, is an associate professor in the University of Southern California School of Social Work.

Correspondence regarding this article should be directed to Katie Massey Combs, 1440 15th St., Boulder, CO 80309 or via e-mail to katie.combs@colorado.edu

\section{References}

Al-Tayyib, A. A., Rice, E., Rhoades, H., \& Riggs, P. (2014). Association between prescription drug misuse and injection among runaway and homeless youth. Drug and Alcohol Dependence, 134, 406-409. https://doi.org/10.1016/j.drugalcdep.2013.10.027

Auerswald, C., \& Puddefoot, G. (2012). Comparing White and African American homeless youth in San Francisco: Research findings and policy implications. Sacramento, CA: California Homeless Youth Project Voices from the Street, CA Research Bureau. Retrieved from http://cahome lessyouth.library.ca.gov/docs/pdf/76146-Compare-WA-Brief-Report.pdf

Barman-Adhikari, A., Al Tayyib, A., Begun, S., Bowen, E., \& Rice, E. (2017). Descriptive and injunctive network norms associated with nonmedical use of prescription drugs among homeless youth. Addictive Behaviors, 64, 70-77. https://doi.org/10.1016/j.addbeh.2016.08 .015

Begun, S. (2015). The paradox of homeless youth pregnancy: A review of challenges and opportunities. Social Work in Health Care, 54(5), 444-460. https://doi.org/10.1080/00981389 .2015.1030058

Bennett, D. A. (2001). How can I deal with missing data in my study? Australian and New Zealand Journal of Public Health, 25(5), 464-469. https://doi.org/10.1111/j.1467-842X.2001 .tb00294.x

Berdahl, T. A., Hoyt, D. R., \& Whitbeck, L. B. (2005). Predictors of first mental health service utilization among homeless and runaway adolescents. Journal of Adolescent Health, 37(2), 145-154. https://doi.org/10.1016/j.jadohealth.2004.08.030

Bousman, C. A., Blumberg, E. J., Shillington, A. M., Hovell, M. F., Ji, M., Lehman, S., \& Clapp, J. (2005). Predictors of substance use among homeless youth in San Diego. Addictive Behaviors, 30(6), 1100-1110. https://doi.org/10.1016/j.addbeh.2004.10.006

Cauce, A. M., Stewart, A., Whitbeck, L. B., Paradise, M., \& Hoyt, D. R. (2005). Girls on their own: Homelessness in female adolescents. In D. Bell, S. L. Foster, \& E. J. Marsh (Eds.), Handbook of behavioral and emotional problems in girls (pp. 439-461). New York, NY: Kluwer Academic.

Chapman, S. L. C., \& Wu, L.-T. (2013). Postpartum substance use and depressive symptoms: A review. Women \& Health, 53(5), 479-503. https://doi.org/10.1080/03630242.2013.804025

Christiani, A., Hudson, A. L., Nyamathi, A., Mutere, M., \& Sweat, J. (2008). Attitudes of homeless and drug-using youth regarding barriers and facilitators in delivery of quality and culturally sensitive health care. Journal of Child and Adolescent Psychiatric Nursing, 21(3), 154-163. https://doi.org/10.1111/j.1744-6171.2008.00139.x 
Collins, P., \& Barker, C. (2009). Psychological help-seeking in homeless adolescents. International Journal of Social Psychiatry, 55(4), 372-384. https://doi.org/10.1177/0020764008094430

Crawford, D. M., Trotter, E. C., Hartshorn, K. J. S., \& Whitbeck, L. B. (2011). Pregnancy and mental health of young homeless women. American Journal of Orthopsvchiatry, 81(2), 173183. https://doi.org/10.1111/j.1939-0025.2011.01086.x

Culhane, D. P., Metraux, S., Park, J. M., Schretzman, M., \& Valente, J. (2007). Testing a typology of family homelessness based on patterns of public shelter utilization in four U.S. jurisdictions: Implications for policy and program planning. Housing Policv Debate, 18(1), $1-$ 28. https://doi.org/10.1080/10511482.2007.9521591

Dworsky, A., \& Meehan, P. (2012). The parenting experiences of homeless adolescent mothers and mothers-to-be: Perspectives from a shelter sample. Children and Youth Services Review, 34(10), 2117-2122. https://doi.org/10.1016/j.childyouth.2012.07.004

Federal Register. (2011). Homeless emergency assistance and rapid transition to housing: Defining "homeless." Federal Register: The Daily Journal of the United States, Rules and Regulations, 76(233), 7594-76019. Retrieved from https://www.hudexchange.info/resources/documents /HEARTH_HomelessDefinition_FinalRule.pdf

Fisher, M., Florsheim P., \& Sheetz, J. (2005). That's not my problem: Convergence and divergence between self-and other-identified problems among homeless adolescents. Child and Youth Care Forum, 34(6), 393-403. https://doi.org/10.1007/s10566-005-7753-9

Goesling, B., Colman, S., Trenholm, C., Terzian, M., \& Moore, K. (2014). Programs to reduce teen pregnancy, sexually transmitted infections, and associated sexual risk behaviors: A systematic review. Lournal of Adolescent Health, 54(5), 499-507. https://doi.org/10.1016/j .jadohealth.2013.12.004

Greene, J. M., Ennett, S. T., \& Ringwalt, C. L. (1999). Prevalence and correlates of survival sex among runaway and homeless youth. American Journal of Public Health, 89(9), 1406-1409. https://doi.org/10.2105/ajph.89.9.1406

Greene, J. M., \& Ringwalt, C. L. (1998). Pregnancy among three national samples of runaway and homeless youth. Iournal of Adolescent Health, 23(6), 370-377. https://doi.org/10.1016/S1054 $-139 X(98) 00071-8$

Grusec, J. E., \& Hastings, P. D. (Eds.). (2014). Handbook of socialization: Theory and research. New York, NY: Guilford Publications.

Haber, M. G., \& Toro, P. A. (2004). Homelessness among families, children, and adolescents: An ecological-developmental perspective. Clinical Child and Family Psychology Review, 7(3), 123-164. https://doi.org/10.1023/B:CCFP.0000045124.09503.f1

Halcón, L. L., \& Lifson, A. R. (2004). Prevalence and predictors of sexual risks among homeless youth. Journal of Youth and Adolescence, 33(1), 71-80. https://doi.org/10.1023/A:1027338514930

Haley, N., Roy, É., Leclerc, P., Boudreau, J. F., \& Boivin, J. F. (2004). HIV risk profile of male street youth involved in survival sex. Sexually Transmitted Infections, 80(6), 526-530. https://doi .org/10.1136/sti.2004.010728

Haley, N., Roy, É., Leclerc, P., Lambert, G., Boivin, J. F., Cedras, L., \& Vincelette, J. (2002). Risk behaviors and prevalence of chlamydia trachomatis and neisseria gonorrhoeae genital infections among Montreal street youth. International Journal of STD \& AIDS, 13(4), 238-245. https://doi.org/10.1258/0956462021925036

Hathazi, D., Lankenau, S. E., Sanders, B., \& Bloom, J. J. (2009). Pregnancy and sexual health among homeless young injection drug users. Journal of Adolescence, 32(2), 339-355. https:II doi.org/10.1016/j.adolescence.2008.02.001

Hodnicki, D. R., \& Horner, S. D. (1993). Homeless mothers' caring for children in a shelter. Issues in Mental Health Nursing, 14(4), 349-356. https://doi.org/10.3109/01612849309006898 
Keeshin, B. R., \& Campbell, K. (2011). Screening homeless youth for histories of abuse: Prevalence, enduring effects, and interest in treatment. Child Abuse \& Neglect, 35(6), 401-407. https://doi.org/10.1016/j.chiabu.2011.01.015

Kidd, S. A. (2004). "The walls were closing in, and we were trapped": A qualitative analysis of street youth suicide. Youth \& Society, 36(1), 30-55. https://doi.org/10.1177/0044118X03261435

Kidd, S. A. (2006). Factors precipitating suicidality among homeless youth: A quantitative follow-up. Youth \& Societv, 37, 393-422. https://doi.org/10.1177/0044118X05282763

Kidd, S. A. (2007). Youth homelessness and social stigma. Iournal of Youth and Adolescence, 36(3), 291-299. https://doi.org/10.1007/s10964-006-9100-3

Luthar, S. S. (2006). Resilience in development: A synthesis of research across five decades. In D. Cicchetti \& D. J. Cohen (Eds.), Developmental psychopathology: Vol. 3. Risk, disorder, and adaptation (2nd ed., pp. 739-795). Hoboken, NJ: Wiley.

Marsiglio, W., \& Pleck, J. H. (2005). Fatherhood and masculinities. In S. Kimmel, J. Hearn, \& R. W. Connell (Eds.), Handbook of studies on men and masculinities (pp. 249-269). London, England: SAGE Publications.

Meadows-Oliver, M. (2006). Homeless adolescent mothers: A metasynthesis of their life experiences. Journal of Pediatric Nursing, 21(5), 340-349. https://doi.org/10.1016/j.pedn.2006.02.004

Menke, E. M., \& Wagner, J. D. (1997). A comparative study of homeless, previously homeless, and never homeless school-aged children's health. Issues in Comprehensive Pediatric Nursing, 20(3), 153-173. https://doi.org/10.3109/01460869709028260

Morton, M. H., Dworsky, A., Matjasko, J. L., Curry, S. R., Schlueter, D., Chávez, R., \& Farrell, A. F. (2018). Prevalence and correlates of youth homelessness in the United States. Iournal of Adolescent Health, 62(1), 14-21. https://doi.org/10.1016/j.jadohealth.2017.10.006

Narayan, A. J. (2015). Personal, dyadic, and contextual resilience in parents experiencing homelessness. Clinical Psychology Review, 36, 56-69. https://doi.org/10.1016/j.cpr.2015.01.005

Narendorf, S. C., Jennings, S. W., \& Maria, D. S. (2016). Parenting and homeless: Profiles of young adult mothers and fathers in unstable housing situations. Families in Societv: The Iournal of Contemporary Social Services, 97(3), 200-211. https://doi.org/10.1606/1044-3894.2016.97.219

Novac, S., Paradis, E., Brown, J., \& Morton, H. (2006). A visceral grief: Young homeless mothers and loss of child custody. Toronto, Ontario: Centre for Urban and Community. Retrieved from http:// www.urbancentre.utoronto.ca/pdfs/elibrary/Novacet-al-206-VisceralGriefHLMothers.pdf

Nyamathi, A., Hudson, A., Greengold, B., \& Leake, B. (2012). Characteristics of homeless youth who use cocaine and methamphetamine. The American Journal on Addictions, 21(3), 243-249. https://doi.org/10.1111/j.1521-0391.2012.00233.x

Nyamathi, A., Hudson, A., Greengold, B., Slagle, A., Marfisee, M., Khalilifard, F., \& Leake, B. (2010). Correlates of substance use severity among homeless youth. Journal of Child and Adolescent Psychiatric Nursing, 23(4), 214-222. https://doi.org/10.1111/j.1744-6171.2010.00247.x

Office of Adolescent Health. (2017). Evidence-based teen pregnancy prevention programs. Retrieved from https://www.hhs.gov/ash/oah/grant-programs/teen-pregnancy-prevention-program -tpp/aboutlindex.html

Panter-Brick, C., Burgess, A., Eggerman, M., McAllister, F., Pruett, K., \& Leckman, J. F. (2014). Practitioner review: Engaging fathers-Recommendations for a game change in parenting interventions based on a systematic review of the global evidence. Iournal of Child Psychology and Psvchiatry, 55(11), 1187-1212. https://doi.org/10.1111/jcpp.12280

Parriott, A. M., \& Auerswald, C. L. (2009). Incidence and predictors of onset of injection drug use in a San Francisco cohort of homeless youth. Substance Use \& Misuse, 44(13), 1958-1970. https://doi.org/10.3109/10826080902865271 
Pearlin, L. I. (1989). The sociological study of stress. Journal of Health and Social Behavior, 30(3), 241-256. https://doi.org/10.2307/2136956

Peterson, P. L., Baer, J. S., Wells, E. A., Ginzler, J. A., \& Garrett, S. B. (2006). Short-term effects of a brief motivational intervention to reduce alcohol and drug risk among homeless adolescents. Psychology of Addictive Behaviors, 20(3), 254-264. https://doi.org/du.idm.oclc.org 110.1037/0893-164X.20.3.254

Rabinovitz, S., Desai, M., Schneir, A., \& Clark, L. (2010). No way home: Understanding the needs and experiences of homeless youth in Hollywood. Homeless Youth Partnership: Hollywood, CA. Retrieved from http://www.hhyp.org/downloads/HHYP_TCE_Report_11-17-10.pdf

Rice, E., Milburn, N. G., \& Monro, W. (2011). Social networking technology, social network composition, and reductions in substance use among homeless adolescents. Prevention Science, 12(1), 80-88. https://doi.org/10.1007/s11121-010-0191-4

Rice, E., Milburn, N. G., \& Rotheram-Borus, M. J. (2007). Pro-social and problematic social network influences on HIVIAIDS risk behaviours among newly homeless youth in Los Angeles. AIDS Care, 19(5), 697-704. https://doi.org/10.1080/09540120601087038

Rice, E., Monro, W., Barman-Adhikari, A., \& Young, S. D. (2010). Internet use, social networking, and HIVIAIDS risk for homeless adolescents. Journal of Adolescent Health, 47(6), 610 613. https://doi.org/10.1016/j.jadohealth.2010.04.016

Rosenthal, D., Mallett, S., Milburn, N., \& Rotheram-Borus, M. J. (2008). Drug use among homeless young people in Los Angeles and Melbourne. Iournal of Adolescent Health, 43(3), 296305. https://doi.org/10.1016/j.jadohealth.2008.06.002

Roy, É., Godin, G., Boudreau, J. F., Côté, P. B., Denis, V., Haley, N., . . Boivin, J. F. (2011). Modeling initiation into drug injection among street youth. Journal of Drug Education, 41(2), 119-134. https://doi.org/10.2190/DE.41.2.a

Ruttan, L., Laboucane-Benson, P., \& Munro, B. (2012). Does a baby help young women transition out of homelessness? Motivation, coping, and parenting. Journal of Family Social Work, 15(1), 34-49. https://doi.org/10.1080/10522158.2012.64271

Schindler, H. S., \& Coley, R. L. (2007). A qualitative study of homeless fathers: Exploring parenting and gender role transitions. Family Relations, 56(1), 40-51. https://doi.org/10.1111/j .1741-3729.2007.00438.x

Slesnick, N., Bartle-Haring, S., Glebova, T., \& Glade, A. C. (2006). Homeless adolescent parents: HIV risk, family structure and individual problem behaviors. Journal of Adolescent Health, 39(5), 774-777. https://doi.org/10.1016/j.jadohealth.2006.04.021

Smid, M., Bourgois, P., \& Auerswald, C. L. (2010). The challenge of pregnancy among homeless youth: Reclaiming a lost opportunity. Journal of Healthcare for the Poor and Underserved, 21(2 Suppl), 140-156. https://doi.org/10.1353/hpu.0.0318

Stein, J. A., Lu, M. C., \& Gelberg, L. (2000). Severity of homelessness and adverse birth outcomes. Health Psychology, 19(6), 524-534. https://doi.org/10.1037/0278-6133.19.6.524

Stewart, A. J., Steiman, M., Cauce, A. M., Cochran, B. N., Whitbeck, L. B., \& Hoyt, D. R. (2004). Victimization and posttraumatic stress disorder among homeless adolescents. $\underline{\text { Iournal of }}$ the American Academy of Child \& Adolescent Psychiatry, 43(3), 325-331. https://doi.org/10.1097 100004583-200403000-00015

Substance Abuse and Mental Health Services Administration. (2011). Results from the $2010 \mathrm{Na}-$ tional Survey on Drug Use and Health: Summary of national findings (NSDUH Series H-41, HHS Publication No. (SMA) 11-4658). Rockville, MD: Author. Retrieved from https://www .samhsa.gov/data/sites/default/files/NSDUHNationalFindingsResults2010-web/2k10ResultsRev INSDUHresultsRev2010.pdf 
Swick, K. J., \& Williams, R. (2010). The voices of single parent mothers who are homeless: Implications for early childhood professionals. Early Childhood Education Iournal, 38(1), 49-55. https://doi.org/10.1007/s10643-010-0378-0

Tevendale, H. D., Lightfoot, M., \& Slocum, S. L. (2009). Individual and environmental protective factors for risky sexual behavior among homeless youth: An exploration of gender differences. AIDS and Behavior, 13(1), 154-164. https://doi.org/10.1007/s10461-008-9395-Z

Thompson, S. J. (2005). Risk/protective factors associated with substance use among runawayl homeless youth utilizing emergency shelter services nationwide. Substance Abuse, 25(3), 13-26. https://doi.org/10.1300/J465v25n03_02

Thompson, S. J., Bender, K. A., Lewis, C. M., \& Watkins, R. (2008). Runaway and pregnant: Risk factors associated with pregnancy in a national sample of runaway/homeless female adolescents. Iournal of Adolescent Health, 43(2), 125-132. https://doi.org/10.1016/j.jadohealth .2007.12.015

Tucker, J. S., Sussell, J., Golinelli, D., Zhou, A., Kennedy, D. P., \& Wenzel, S. L. (2012). Understanding pregnancy-related attitudes and behaviors: A mixed-methods study of homeless youth. Perspectives on Sexual and Reproductive Health, 44(4), 252-261. https://doi.org/10.1363/4425212

Tyler, K. A. (2008). Social network characteristics and risky sexual and drug related behaviors among homeless young adults. Social Science Research, 37(2), 673-685. https://doi.org/10.1016/j .ssresearch.2007.09.004

Tyler, K. A., \& Beal, M. R. (2010). The high-risk environment of homeless young adults: Consequences for physical and sexual victimization. Violence and Victims, 25(1), 101-115. https://doi .org/10.1891/0886-6708.25.1.101

Wagner, L. S., Carlin, L., Cauce, A. M., \& Tenner, A. (2001). A snapshot of homeless youth in Seattle: Their characteristics, behaviors and beliefs about HIV protective strategies. Iournal of Community Health, 26(3), 219-232. https://doi.org/10.1023/A:1010325329898

Walls, N. E., \& Bell, S. (2011). Correlates of engaging in survival sex among homeless youth and young adults. Iournal of Sex Research, 48(5), 423-436. https://doi.org/10.1080/00224499 .2010 .501916

Warf, C. W., Clark, L. F., Desai, M., Rabinovitz, S. J., Agahi, G., Calvo, R., \& Hoffmann, J. (2013). Coming of age on the streets: Survival sex among homeless young women in Hollywood. Journal of Adolescence, 36(6), 1205-1213. https://doi.org/10.1016/j.adolescence.2013.08.013

Wenzel, S. L., Tucker, J. S., Golinelli, D., Green, H. D., \& Zhou, A. (2010). Personal network correlates of alcohol, cigarette, and marijuana use among homeless youth. Drug and Alcohol Dependence, 112(1), 140-149. https://doi.org/10.1016/j.drugalcdep.2010.06.004

Winetrobe, H., Rhoades, H., Barman-Adhikari, A., Cederbaum, J., Rice, E., \& Milburn, N. (2013). Pregnancy attitudes, contraceptive service utilization, and other factors associated with Los Angeles homeless youths' use of effective contraception and withdrawal. $\underline{\text { ournal }}$ of Pediatric and Adolescent Grnecology, 26(6), 31-322. https://doi.org/10.1016/j.jpag.2013.06.007

Manuscript submitted: April 27, 2018

First revision submitted: August 6, 2018

Second revision submitted: September 10, 2018

Third revision submitted: September 11, 2018

Accepted: September 12, 2018

Electronically published: December 17, 2019 